\title{
ANÁLISE DA IMPLEMENTAÇÃO DA POLÍTICA MUNICIPAL DE EDUCAÇÃO AMBIENTAL NO MUNICÍPIO DE NATAL/RN
}

\section{REVIEW OF THE IMPLEMENTATION OF THE POLICY OF MUNICIPAL ENVIRONMENTAL EDUCATION IN THE MUNICIPALITY OF NATAL/RN}

\author{
Ana Luiza Bezerra Fernandes', Carlos Enrique de Medeiros Jerônimo (Orientador) ${ }^{2}$ \\ ${ }^{1}$ Especialista em Pericia e Gestão Ambiental. analuizabezerra@bol.com.br \\ ${ }^{2}$ Doutorado em Engenharia Quimica. Engenheiro de Processamento de Petroleo da Petrobras. \\ c enrique@hotmail.com
}

http://dx.doi.org/10.5902/223613087653

\section{RESUMO}

O objetivo geral desta pesquisa é analisar a implementação da Política Municipal de Educação Ambiental no Município de Natal/RN (PMEAN). Para se alcançar este objetivo foi necessário identificar as atividades, ações, procedimentos, técnicas, mecanismos de participação popular e aportes financeiros que estão sendo utilizadas pelos gestores da referida política, para envolver os indivíduos e a coletividade dos cenários da educação formal, e não formal acerca da Educação Ambiental. A metodologia utilizada para analisar as estratégias de implementação da política em análise foi a consulta bibliográfica sobre o tema; a pesquisa em sites sobre artigos científicos relacionados ao tema, a apreciação de documentos, de experiências práticas, das instâncias de diálogo e pactuação de políticas, programas, projetos, planos políticos e pedagógicos; a aplicação de questionários abertos com abordagem qualitativa sobre o contexto temático. O público alvo desta investigação foi gestores municipais das Secretarias Municipais de Educação e de Meio Ambiente, professores de ensino fundamental das escolas públicas e particulares do município de Natal, discentes das referidas escolas e moradores de comunidades do espaço citadino natalense. Para a obtenção dos resultados desta pesquisa foi considerada a validação e efetivação das estratégias de implementação da PMEAN. Em razão disto, o estudo dos elementos investigados tiveram como parâmetro o estabelecido pela Lei 9795/99, da Política Nacional de Educação Ambiental do Brasil.

Palavras-chave: Educação Ambiental. Política Ambiental. Participação Popular.

\section{ABSTRACT}

The overall goal of this research is to analyze the implementation of the Common Municipal Environmental Education in the city of Natal / RN (PMEAN). To achieve this goal it was necessary to identify the activities, actions, procedures, techniques, mechanisms for popular participation and financial contributions that are being used by the managers of the policy, to engage individuals and the collectivity of the scenarios of formal and non-formal about environmental education. The methodology used to analyze the strategies of implementation of the policy in 
question was to consult the literature on the subject, the research sites on scientific articles related to the topic, the examination of documents, practical experiences, instances of dialogue and agreement policies, programs, projects, plans, political and pedagogical; applying qualitative approach with open questionnaires on thematic context. The target of this investigation was municipal managers of Municipal and Environmental Education, elementary school teachers from public and private schools of the city of Natal, students of these schools and residents of communities the space Natal city. To obtain the results of this research was considered the validation and effectiveness of implementation strategies of PMEAN. For this reason, the study of the elements was investigated as parameters established by Law 9795/99, the National Environmental Education Politics in Brazil.

Keywords : Environmental Education. Environmental Politics. Popular Participation.

\section{INTRODUÇÃO}

Na década de 60, o acelerado crescimento econômico e industrial e os avanços científicos e tecnológicos geraram problemas ambientais que provocaram uma abrupta queda na qualidade de vida da população mundial. Segundo Leff (2001, p.15-16), "a crise ambiental se tornou evidente nos anos 60, refletindo-se na irracionalidade ecológica dos padrões dominantes de produção e consumo, e marcando os limites do crescimento econômico".

No ano de 1962, em seu livro Primavera Silenciosa, a jornalista Rachel Carson traz ao conhecimento da humanidade os desastres ambientais, em diversas regiões do mundo, ocasionados pelo descuido dos setores industriais. Buscado pelo público ambientalista, ecologista e preservacionista, o livro torna-se um clássico no universo das discussões ambientais e fomenta uma grande agitação internacional em torno do tema. Tais agitações fazem a delegação da Suécia chamar a atenção da comunidade internacional para a crescente crise do meio ambiente humano alertando de modo oficial, pioneiramente, sobre a necessidade de uma abordagem planetária para a busca de soluções contra o recrudescimento da degradação ambiental (DIAS, 1991).

Segundo Santos (2007), enquanto os governos não clarificavam a definição do entendimento internacional sobre a questão ambiental do planeta, vários segmentos sociais começaram a produzir respostas. Esses segmentos questionavam os estilos de vida, valores e comportamentos da sociedade contemporânea, por meio de denuncias alusivas aos países capitalistas, consumistas e aos países pobres produtores de matérias-primas.

Em 1965 acontece a Conferência de Keele, na Grã-Bretanha, onde educadores se reúnem e acordam para a inserção da Educação Ambiental (EA) na escola e na vida de todos os cidadãos. Em 1969, no mesmo país, foi fundada a Sociedade de Educação Ambiental. Nesse contexto, artistas, políticos e a imprensa européia davam ênfase ao tema fortalecendo e popularizando o início de uma mobilização em favor da Ecologia (DIAS, 1991).

Em 1966, o manual A place to live, (Um lugar para viver), é publicado pela Sociedade Audubon. Este seria destinado a professores que incorporavam a dimensão ambiental nas atividades curriculares e viria a se tornar um clássico sobre o tema. Neste período, no Brasil, acontecia o prenúncio dos movimentos ambientalistas com a fundação da Associação Gaúcha de Proteção ao Ambiente Natural. 
Em 1968, o Clube de Roma - grupo de trinta cientistas, de várias áreas, dos países desenvolvidos, convocados pela Organização das Nações Unidas (ONU) - reuniram-se em Roma para discutirem sobre a crise vivenciada pela população mundial e o futuro da humanidade. Essa discussão foi publicada pelo referido Clube no relatório The Limits of grawth (Os limites do crescimento econômico). De acordo com Dias (1991, p.3) "O documento condenava a busca incessante do crescimento da economia a qualquer custo, e a meta de se torná-la cada vez maior, mais rica e poderosa, sem levar em conta o custo final desse crescimento".

Em 1972, os resultados do relatório supracitado foram levados à Conferência da ONU sobre o Ambiente Humano - A Conferência de Estocolmo na Suécia. Nessa reunião, os representantes de 113 países chamaram a atenção de todo o planeta para ações humanas que estavam ocasionando uma série de destruições na natureza. Para Leff (2002, p. 151) "Os movimentos ambientalistas emergem como resposta da sociedade à crescente deterioração ambiental". No ano de 1972 aconteceram os eventos mais significativos para o meio ambiente do planeta por provocarem mudanças, ou propostas de mudanças nos rumos da história ambiental da humanidade.

$\mathrm{Na}$ Conferência de Estocolmo foi recomendada a criação do Programa das Nações Unidas para o Meio Ambiente e Desenvolvimento - PNUMA, concretizado no ano seguinte (SANTOS, 2007, p. 59). Nessa época, pelo fato do PNUMA ainda não está institucionalizado, não havia uma preocupação por parte dos governos e o assunto não fazia parte da agenda internacional.

Gadotti $(2009$, p.42) relata que:

A Conferência de Estocolmo preocupou-se com o problema da pobreza e da distribuição de renda, mas o foco mesmo era a poluição causada pelas atividades humanas, particularmente pelo desenvolvimento industrial, que degradavam o meio ambiente. Os países ricos reconheceram que eram eles que mais poluíam a Terra, mas não discutiram como evitar a poluição. Diziam que era o custo que se pagava pelo "progresso".

O resultado final dessa reunião foi a Declaração sobre o Ambiente Humano que ressaltava a responsabilidade das pessoas na conservação do meio ambiente. A Recomendação n. 96 da Conferência reconhecia o desenvolvimento da EA como o elemento crítico para o combate à crise ambiental do mundo.

Em 1975, após Estocolmo, ocorre o I Encontro Internacional de EA em Belgrado (Iugoslávia) onde foram formulados os princípios e orientações para um programa internacional de EA (CARTA DE BELGRADO). Esse documento tinha como intenção que o desenvolvimento da EA fosse um dos meios para acabar com a crise do meio ambiente, além de propiciar uma nova ética global.

Na Carta de Belgrado foi sugerida pelo PNUMA, a prática da Educação Ambiental em todos os organismos internacionais. Com isso, foram definidos seis objetivos indicativos da Educação Ambiental, como relata Santos (2007, p.59),

O CONHECIMENTO do meio ambiente global, seus problemas e responsabilidade dos indivíduos e grupos com a CONSCIENTIZAÇÃO que SENSIBILIZA e provoca mudanças no COMPORTAMENTO, as quais contribuem para a proteção e qualidade do meio ambiente. Nesse processo, é necessário reconhecer que a COMPETÊNCIA passa pela associação da técnica aos conhecimentos autoditadas e serve para as AVALIAÇÕES PERMANENTES das medidas e programas com vistas a solucionar muitos problemas ambientais. 
Após o Encontro de Belgrado, no Brasil, o debate sobre a EA acontecia por meio de alguns órgãos estaduais ligados ao meio ambiente e nos setores educacionais. Estes entendiam a EA como Ecologia orientada para o estudo das águas, do solo, do ar, das florestas e dos animais em extinção não incluindo, nas discussões, questões sobre o modelo de desenvolvimento excludente, - combate a pobreza e a miséria, a degradação do patrimônio biológico e cultural, as desigualdades sociais, a subordinação econômica que geram a destruição da qualidade socioambiental.

Com a evolução dos debates e discussões acerca do presente e do futuro ambiental do planeta, nos meados da década de 70 do século XX, o marco teórico de maior relevância para a Educação Ambiental e que veio dar continuidade ao Seminário de Belgrado (ibid, 2007), ocorreu no ano de 1977 com a Conferência Intragovernamental de Educação Ambiental em Tbilisi, na Georgia, Ex-URSS.

De acordo com Dias (1991, p.5), A "Conferência de Tbilisi", como ficou conhecida, foi o ponto culminante da primeira fase do Programa Internacional de Educação Ambiental, iniciado em Belgrado (1975), e contribuiu para precisar a natureza da EA, definindo seus objetivos, características, recomendações e estratégias pertinentes no plano nacional e internacional. Ou seja, tudo o que se precisava saber para o início do desenvolvimento da EA foi deixado em Tbilisi.

O documento final da reunião de Tbilisi corroborou algumas conclusões da carta de Belgrado e sugeriu ações específicas para atingir seus objetivos fortalecendo a Educação Ambiental. No escrito, o objetivo da Educação Ambiental era o de contribuir para que houvesse um espírito de responsabilidade e de solidariedade entre os países e regiões, e assim, teria como base uma nova ordem internacional, garantindo a conservação e a melhoria do meio ambiente.

Não obstante, o documento supracitado prevê que o papel da EA é de promover uma aproximação sinérgica entre os processos educativos e a realidade das pessoas. Ou seja, suas atividades deveriam estar ligadas aos problemas concretos vividos pela comunidade que deveria ser trabalhada de forma interdisciplinar e holística, permitindo a compreensão interrelacional dos problemas, devendo ser concebida como um processo contínuo, adaptando o saber às condições variáveis do meio.

A Educação Ambiental (ibid, 2007, p. 60), deve ajudar a descobrir os sintomas e as causas reais dos problemas ambientais, destacar a sua complexidade ambiental e, em consequência, a necessidade de desenvolver o censo critico e as habilidades necessárias para resolver os problemas, utilizar diversos ambientes educativos e uma ampla gama de métodos para comunicar e adquirir conhecimentos sobre o meio ambiente, acentuando devidamente as atividades práticas e as experiências pessoais.

Por sua vez, Dias (1991, p.5) afirma que "A conferência de Tbilisi nos legou as premissas básicas da EA, testadas e corroboradas até os dias atuais". Nesse sentido, observa-se que a Conferência de Tbilisi, em seus escritos, orienta para a promoção de uma EA que, por meio das suas atividades, propõe que os indivíduos e a coletividade conheçam e compreendam o ambiente em que vivem, harmonizem-se entre si e com o meio e tenham atitudes positivas, competências e habilidades para proteger e melhorar o ambiente participando ativamente no contexto socioambiental local e global das suas vivências. 
Em conseqüência da Conferência de Estocolmo e sob pressão do Banco Mundial e instituições ambientalistas, o governo brasileiro criou a Secretaria especial de Meio Ambiente SEMA para, juntamente com o MEC, gerenciar as questões e discussões pertinentes ao contexto ambiental brasileiro.

Em 1979 o Ministério da Educação do Brasil (MEC) e a CETESB publicaram o documento Ecologia - uma proposta para o ensino de 10 e 20 graus. A publicação fez uma abordagem reducionista da temática ambiental priorizando os aspectos biológicos do meio ambiente. Tendo em vista que havia sido realizada uma Conferência Internacional sobre EA onde especialista de várias áreas esboçaram os princípios basilares numa perspectiva holística para o desenvolvimento da EA, com isso, ficou demonstrada a confusão conceitual acerca do entendimento da EA por parte daqueles que, no momento vigente, discutiam e orientavam sobre os princípios e práticas da Educação Ambiental no Brasil.

$\mathrm{Na}$ efervescência da ditadura militar, em 1981, o movimento ambientalista brasileiro concretiza sua primeira conquista com a publicação da Lei 6.938, que dispunha sobre a Política Nacional de Meio Ambiente. Essa Lei representou um significativo mecanismo de aprimoramento e consolidação da política ambiental em nosso país. Porém, no tocante a EA esta continuou sendo abordada pela prática do "ecologismo", ou seja, a vertente educacional da política ambiental brasileira não discutia os aspectos sociais, políticos, econômicos, culturais, éticos e demais fatores importantes de serem compreendidos e considerados no desenvolvimento da EA.

A Comissão Mundial de Meio Ambiente vinha realizando várias reuniões sob a coordenação da primeira ministra norueguesa Gro Harlem Brundtland. (ibid, 2007). Desses encontros, em 1987, decorreu o Relatório Brundtland que definiu o conceito de desenvolvimento sustentável, recomendou e forneceu os subsídios teóricos e metodológicos para a realização de uma reunião mundial na década de 1990, conhecido como Eco-92.

O supramencionado relatório conceituou desenvolvimento sustentável como novo padrão de desenvolvimento capaz de garantir as necessidades das gerações presentes sem comprometer as gerações futuras. [...] a Educação Ambiental como proposta pedagógica, questionava o paradigma do desenvolvimento sustentável, a visão de mundo e de valores humanos que fundamentam as relações entre a sociedade e a natureza. Nesse mesmo ano (1987) da publicação do Relatório Brundtland, a UNESCO realiza em Moscou-Rússia, a II Conferência Intergovernamental sobre Educação Ambiental. De acordo com Dias (1991, p.8),

[...] o Plenário do Conselho Federal de Educação (MEC) aprovou, por unanimidade, a conclusão da Câmara de Ensino, a respeito do Parecer 226/87 que considerava necessária a inclusão da EA dentre os conteúdos a serem explorados nas propostas curriculares das escolas de 10 e 20 graus. [...] A verdade é que chegávamos à segunda conferência intergovernamental de EA sem que tivéssemos iniciado nem mesmo o desenvolvimento de recursos instrucionais para a prática da EA em nossas escolas. Imaginem a nível nãoformal...

Em 1988 as entidades ambientalistas civis brasileiras se articulam e fortalecem os esforços em prol da inserção das questões ambientais no texto da Constituição Federal do Brasil (CF), então promulgada. Dessas articulações e esforços conjuntos resultou no Capítulo VI, da CF, sobre o meio ambiente e muitos artigos afins, dentre estes o de maior abrangência foi o Art. 225. "Todos têm direito ao meio ambiente ecologicamente equilibrado, bem de uso comum do povo e essencial à 
sadia qualidade de vida, impondo-se ao Poder Público e à coletividade o dever de defendê-lo e preservá-lo para as presentes e futuras gerações".

Com efeito, a crise ambiental não poderia mais ser tratada isolada das estruturas políticas, sociais, culturais e educacionais (ibid, 2007, p. 62). Ficou evidente a necessidade de educar para, com e no ambiente. Gadotti (2009, p. 98) afirmou que era possível um equilíbrio dinâmico entre equidade, crescimento meio ambiente. [...] reconhece, porém, que, para haja esse equilíbrio, são necessárias profundas mudanças sociais e tecnológicas. [...] define três componentes fundamentais do desenvolvimento sustentável - a proteção ambiental, o crescimento econômico e a equidade social. Para isso, a relação entre nações desenvolvidas e não desenvolvidas deve mudar.

No ano de 1992, foi realizada a Conferência das Nações Unidas, Meio Ambiente e Desenvolvimento Sustentável (CNUMAD-92) ou Rio-92, na cidade do Rio de Janeiro. "Essa conferência destacou a importância da Educação Ambiental no contexto das ações educativas visando à conservação do meio ambiente para as presentes e futuras gerações" (ibid, 1999, p. 129).

Dos vários compromissos acordados na Rio-92, um dos que obteve maior destaque foi a Agenda 21 que, de acordo com Medina \& Santos (1999, p. 129), "consagra o capítulo 36 à promoção da educação, da consciência política e do treinamento" e apresenta um plano de ação para o desenvolvimento sustentável, a ser adotado pelos países, a partir de uma nova perspectiva para a cooperação internacional. Como expressa Czapski (2009, p.290) "Foi nela que se finalizou a construção do Tratado de Educação Ambiental para as Sociedades Sustentáveis e Responsabilidade Global, referência para quem quer fazer EA em qualquer parte do mundo".

Paralelamente à conferência, o Brasil realiza eventos que resultam na aprovação da "Carta Brasileira para a Educação Ambiental". Essa carta coloca o Estado como definitivo agente da implantação da EA no país, com a criação do Ministério do Meio Ambiente. Após a conferência, o MEC tentou implantar um pano nacional das bases da educação ambiental que não foi realizado devido á falta de informação das instituições educacionais sobre o tema.

Por instrução conjunta do Ministério da Educação e Cultura, do Ministério do Meio Ambiente e do Ministério da Ciência e Tecnologia, a Presidência da República institui, em 1994, o Programa Nacional de Educação Ambiental - ProNEA. Este Programa foi reorganizado em 2004.

\footnotetext{
Para Loureiro (2008, p.7-8), Propõe compreender as especificidades dos grupos sociais, o modo como produzem seus meios de vida, como criam condutas e se situam na sociedade, para que se estabeleçam processos coletivos pautados no diálogo, na problematização do mundo e na ação. Com isso, passa-se a ter, por pressuposto, que é a transformação das condições materiais e simbólicas que expressa a concretude do ato educativo na superação das formas alienadas de existência e das dicotomias entre sociedade-natureza.
}

Pelo que instrui o ProNEA, a missão da Coordenação de Educação Ambiental do MEC (COEA/MEC), era desenvolver uma EA orientada para a educação formal em todos os níveis de ensino. "Para os demais públicos, que não o escolar, a execução caberia aos setores correspondentes do MMA/lbama, focando-se em especial a educação no processo de Gestão Ambiental" (Czapski, 2009, p.33). 
Pela concepção de muitos especialistas, 1997 foi o ano da EA no Brasil e no mundo. Destes eventos pode-se citar: II Congresso Iberoamericano de EA (Guadalajara/México), IV Fórum Brasileiro de EA, ao qual se associou o I Encontro da Rede Brasileira de EA (Rebea) em Guarapari (ES), 1a Conferência Nacional de EA (CNEA), realizada em Brasília (DF), Conferência Internacional sobre Meio Ambiente e Sociedade: Educação e Consciência Pública para a Sustentabilidade em Thessaloniki (Grécia). Segundo Czapski (2009, p.29) "Foi um período recheado de novidades, que instigaram milhares de educadoras/es a participar de diferentes eventos, nacionais e internacionais".

Na busca pelo amparo legal para o debate sobre a educação ambiental, no ano de 1999, o Governo brasileiro promulga a Lei no 9795 que dispõe sobre a Política Nacional de Educação Ambiental-PNEA. De acordo com Loureiro $(2008$, p.7) "Após a regulamentação da Lei que define a PNEA, em 2002, [...] a Educação Ambiental assume uma dinâmica intensa em termos políticoinstitucionais e de projetos de formação de amplos setores sociais". A PNEA regulamenta a inserção da temática ambiental nas instituições de ensino brasileiras, facilita o desenvolvimento da EA e a implantação do ProNEA nas escolas de todo país.

Passados dez anos da Eco-92, a ONU organizou, na cidade de Johanesburgo, na África do Sul, no ano de 2002, a Cúpula Mundial Sobre Desenvolvimento Sustentável, conhecida como Rio+10. Nesse encontro os representantes de países do mundo inteiro reafirmaram alguns acordos assinados na Rio-92 principalmente o de colocar em prática as recomendações do documento composto por 2.500 itens, conhecido como Agenda 21. Segundo Gadotti (2009, p. 4445),

\footnotetext{
Constatou-se o fracasso das medidas tomadas dez anos antes. O mundo tomava conhecimento de que a maior consciência ecológica que se seguiu a Rio-92 não fora suficiente para evitar o desastre confirmado logo a seguir (2006 e 2007) pelo Painel Intergovernamental sobre Mudanças Climáticas (IPCC). O aquecimento global já não é um episódio distante. Seus efeitos já começaram a fazer-se sentir em todo o planeta. [...] não temos mais escolha: ou mudamos o nosso modo de produzir e reproduzir nossa existência no planeta ou simplesmente morreremos.
}

Em 16 de julho de 2009, o Governo Municipal de Natal promulga a Lei no 0280 que dispõe sobre a educação ambiental e institui a Política Municipal de Educação Ambiental e dá outras providências. Em 2005, o Governo Municipal de Natal/RN cria a Lei 5687 que institui o Núcleo Municipal de Educação Ambiental de Natal. No Artigo 10 da referida Lei "Fica instituído o Núcleo Municipal de Educação Ambiental - NEA, com a finalidade de promover a Educação Ambiental, em seus aspectos formais e não formais, através da discussão, gestão, coordenação, acompanhamento, avaliação e implementação das atividades de educação ambiental no Município".

Em junho de 2012, na cidade do Rio de Janeiro, a ONU reuniu 188 países para realizar a Conferência sobre Desenvolvimento Sustentável, Rio +20 . Uma das expectativas Rio+20 era de que a reunião conseguisse determinar metas de desenvolvimento sustentável em diferentes áreas, mas isso não foi atingido. $O$ documento final da conferência, intitulado "O futuro que queremos", apenas cita que eles devem ser criados a partir de 2015.

Diante do exposto, este artigo científico tem como objetivo geral analisar a aplicação da Política Municipal de Educação Ambiental no Município de Natal/RN (PMEAN. Nesse sentido, além de se fazer necessário contextualizar a educação ambiental na história do ambientalismo, assim 
como seus desdobramentos nas áreas da educação formal e não formal é interessante entender o significado da expressão Política Municipal. No dicionário Aurélio, uma das definições dadas ao termo política "é o Conjunto de objetivos que enformam determinado programa de ação governamental e condicionam a sua execução".

Sendo assim, balizamos que esse estudo desdobra o processo de implementação da EA destacando a necessidade de definição de políticas públicas, especificamente no que diz respeito às diretrizes de educação ambiental implantadas no município de Natal. É notório que os problemas socioambientais influenciaram aos Estados e Municípios a pensarem em políticas públicas tendo em vista (re)educar a sociedade com uma educação que se propõe a estimular processos continuados que possibilitem o respeito a diversidade biológica, cultural e étnica.

\section{METODOLOGIA}

Este estudo trata-se de uma pesquisa qualitativa, pois tem como um dos seus objetivos averiguar sobre aspectos relativos ao indivíduo em seus múltiplos relacionamentos com outros indivíduos e instituições sociais. A escolha por métodos qualitativos de pesquisa se deu em virtude da importância pelo emprego da observação como premissa por ter-se em conta que,

A metodologia qualitativa é aquela que incorpora a questão do significado e da intencionalidade como inerentes aos atos, às relações e às estruturas sociais. $O$ estudo qualitativo pretende apreender a totalidade coletada visando, em última instância, atingir o conhecimento de um fenômeno histórico que é significativo em sua singularidade. MINAYO (1994, p.10).

Do ponto de vista dos objetivos, trata-se de um estudo exploratório-descritivo, o qual visa descrever a problemática em discussão, buscando caracterizar o objeto de estudo. Bem como, fazendo um estudo comparativo às pesquisas desenvolvidas para metodologia de elaboração e implantação de políticas de gestão ambiental, com vistas aos elementos da educação ambiental.

O estudo envolve também, como procedimento técnico, a pesquisa bibliográfica por sua elaboração partir do levantamento e análise de material já publicado, como artigos científicos, livros, relatórios técnicos, etc. e (Gil, 2007), e como estudo de caso devido à utilização de dados de campo.

A estrutura da pesquisa consiste em:

- Formulação do problema, englobando a justificativa do estudo, a determinação dos objetivos, a contextualização da problemática e definição da metodologia;

- Realização do levantamento teórico, que orienta a caracterização do objeto de estudo, as definições e conceitos a serem utilizados em análise e correntes de pensamentos que norteiam a hipótese da pesquisa;

- Levantamento de dados em campo, por meio de incursões investigativas em diferentes níveis de gestão da política municipal de Natal, frente aos elementos econômicos, planejamento e execução;

- Realização de uma análise estatística dos dados obtidos e desdobramento numa análise de indicadores práticos. 
Os dados coletados em campo foram organizados, de acordo com a necessidade da utilização em pesquisa, e utilizados para elaboração do levantamento das principais ações de oportunidades.

As principais questões avaliadas com os entrevistados foram:

1. Qual (is) é (são) o(s) órgão(s) gestor (ES) responsável(is) direta e indiretamente pelo desenvolvimento da Educação Ambiental (EA) no município de Natal/RN? Se há como se articula $(\mathrm{m})$ esse(s) responsável (is)?

2. Quais ações, procedimentos, técnicas e mecanismos de participação popular estão sendo utilizadas pelos gestores no desenvolvimento da EA no Município para envolver os indivíduos e a coletividade?

3. Quais questões socioambientais estão sendo abordadas dos cenários da EA? Essas questões são abordadas nos cenários da educação formal, informal e não formal acerca da Educação Ambiental?

4. O município em questão possui uma Política Municipal de EA (PMEAN)? Quais são seus princípios, diretrizes e práticas?

5. Caso exista uma PMEAN, quais os aportes financeiros utilizados na aplicação dessa política?

\section{RESULTADOS E DISCUSSÕES}

O objetivo do presente trabalho é analisar como a Política Municipal de Educação Ambiental está sendo executada ou implementada no município de Natal/RN. Para a gestão do meio ambiente, existe o Sistema Nacional de Meio Ambiente (SISNAMA), instituído pela Lei no 6.938/81; enquanto para a educação formal, a Lei de Diretrizes e Bases (LDB) estabelece suas normas fundamentais e organiza os entes federativos para o cumprimento do Plano Nacional de Educação (PNE).

Para que um estado ou município execute de maneira compartilhada e mais eficiente uma Política de Educação Ambiental precisa-se que estes tenham, no mínimo, dois conselhos: o Conselho Municipal de Educação - CME, (responsável pela Educação formal conforme a Seção II, artigo 9o à 12ㅇda Lei no 9.795/99) e o Conselho Municipal de Meio Ambiente - CONDEMA, (ficando a cargo de executar a Educação não formal de acordo com a Seção III, artigo 13 Inciso de I à VII da Lei no 9.795/99 que institui a Política Nacional de Educação Ambiental-PNEA). Conforme descrito numa das diretrizes consagradas pelo Programa Nacional de Educação Ambiental-ProNEA, para que uma política atinja suas metas, é preciso que haja a descentralização Espacial e Institucional: de poder e da gestão-administrativa, com a partilha de competências e atribuições entres os atores, instituições e órgãos da PNEA, havendo incentivo ao desenvolvimento de políticas regionais de Educação Ambiental, e tendo como premissa que a intervenção do poder público (Estado) deve subsidiar o protagonismo da sociedade.

. A Lei no0280/2009 institui a Política Municipal de Educação Ambiental de Natal e dispõe sobre a Educação Ambiental (EA) no município. Esta lei em seu Art. 3o, inciso III estabelece que: cabe ao Conselho Municipal de Meio Ambiente, promover ações de educação ambiental integradas aos programas de conservação recuperação e melhoria do ambiente. 
Como se pôde ver há uma diferença básica na constituição acerca do órgão gestor da PMEAN e o que reza a PNEA, pois aquela estabelece que apenas o Conselho Municipal de Meio Ambiente é responsável pelas ações de EA integradas aos programas de conservação recuperação e melhoria do ambiente e não cita a necessidade de existir um Conselho Municipal de Educação atuando de forma paritária, articulada e compartilhada visando à execução eficiente da PMEAN.

Ao iniciar as primeiras coletas de informações sobre o processo de implementação da PMEAN ficou constatado que as ações e atividades em educação ambiental são pontuais e acontecem isoladamente.

O órgão legalmente instituído e competente pelas ações de educação ambiental no município de Natal é a SEMURB, através da Secretaria Adjunta de Gestão Ambiental (SAGA) e o Setor de Educação Ambiental (SEA). Existem ainda outros órgãos que também atuam no desenvolvimento das práticas de Educação Ambiental no município: Urbana, SME, SMS, SEMSUR, SEMOB, ARSBAN. Nesse sentido, a grande dificuldade é articular as ações desses órgãos para que elas se tornem mais eficientes e produtivas.

(Entrevista 003, masculino, gestor).

SEMURB, Secretaria Municipal de Educação, órgãos como URBANA, Secretaria de Saúde e ARSBAN $^{1}$ também possuem atribuições. Eles não se articulam, os mesmos realizam suas atribuições de forma pontual.

(Entrevista 001, feminino, gestora).

IDEMA, IBAMA, SEMURB, SEMARH, Secretaria de Educação, URBANA, CAERN, COSERN, UFRN, NEAS, ESCOLAS, EMPRESAS, ONGs, existe meios de articulação entre os órgãos.

(Entrevista 002, feminino, gestora).

O Conselho de Meio Ambiente, que integra o Setor de Educação Ambiental da Secretaria Municipal de Meio Ambiente e Urbanismo-SEMURB, se responsabiliza apenas pela implantação da Comissão de Meio Ambiente e Qualidade de Vida- COM-VIDA/Agenda 21 na escola (organização em Rede, criada pelo governo federal onde todos são iguais em direitos e deveres, todos tem voz ativa e a oportunidade de criar, pensar e participar, político e socialmente pela escola e a comunidade) nas escolas municipais de Natal.

Existe em Natal dentro da secretaria de educação ambiental o conselho de meio ambiente, responsável por implantar nas escolas dos municípios as COMVIDAS - Comissão de Meio Ambiente e Qualidade de Vida, essa comissão é parte integrante dos conselhos escolares, e geralmente é composta por professores, funcionários, pais dos alunos e alunos.

(Entrevista 003, masculino, gestor).

Isso permite assegurar que, apesar da afirmação feita na entrevista 003, de que a abordagem das ações educativas ambientais no município de Natal possuem um foco na qualidade de vida da população e enfocam temas ligados às diversas áreas do contexto socioambiental, as demais entrevistas apontam para a gestão da PMEAN com um foco de execução e atuação na educação formal com a comunidade escolar.

De acordo o Código Nacional de Meio Ambiente (Lei 6938/81) a gestão ambiental é de competência material comum, ou seja, todos, seja de vertente institucional e/ou cidadã, têm o dever de participar e agir na promoção do meio ambiente socialmente justo e ecologicamente 
equilibrado.(1981,grifo nosso). Além disso, de acordo com caput do Art. 8으, Capítulo II, Seção I, da PMEAN, as ações vinculadas à Política Municipal de Educação Ambiental devem ser desenvolvidas na educação formal e não formal e no caput do Art. 13, Seção III, do mesmo Capítulo, entende-se por educação ambiental não formal as ações e práticas educativas voltadas à sensibilização da coletividade sobre a problemática ambiental, e à sua organização e participação na defesa da qualidade do meio ambiente.

Como foi descrito na entrevista 001 as instituições desenvolvem algumas ações de EA, conforme orienta a Lei 6938/81, porém estas não são articuladas com as demais instituições e acontecem de forma pontual. Sendo assim, no município de Natal a PMEAN não possui ações contínuas, com articulação metodológica constante e programada e não têm uma abordagem não formal, ou seja, com enfoque na realidade socioambiental das comunidades.

\footnotetext{
Os conteúdos relacionados à EA são incluídos no conteúdo programático de cada ano letivo (6ㅇ AO 9o ANO) e são trabalhados a partir do livro didático, em pesquisas e trabalhos individuais e coletivos em sala, como: seminário e avaliações.

Ex. poluição sonora, visual, coleta seletiva de lixo, etc.

(Entrevista 004, feminino, educadora).
}

As questões dos efeitos da coletividade na educação formal. (Entrevista 006, masculino, educador).

\begin{abstract}
São questões que perpassam os mais diversos temas associados a qualidade de vida da população, sensibilização e preservação ambiental. Problemas associados ao lixo e saneamento ambiental (saneamento básico, tratamento de esgoto, lançamento de água servida em logradouro, depósito e descarte adequado de lixo), consumo adequado de energia, alimentos e água evitando desperdícios, proteção animal e contensão aos maus tratos, preservação das áreas verdes, orientação as podas e plantio de árvores.

(Entrevista 003, masculino, gestor).
\end{abstract}

Segundo Gadotti (2009) apesar da educação ambiental formal está mais ligada aos sistemas de ensino e a educação ambiental não formal está ligada diretamente a sociedade civil global, as Organizações Não Governamentais (ONGs) e aos movimentos sociais, não nos colocam em questão qual delas é a mais importante: "não creio que o formal e o não formal sejam realmente paradigmas contraditórios; creio, sim, que sejam complementares. Uma estratégia não exclui a outra". (p. 99).

Dessa forma, gestores, educadores, lideres comunitários, agentes políticos, entre outros devem entender política de educação ambiental como um sistema intricado com várias interrelações evidenciando as peculiaridades da coletividade podendo utilizar-se de uma só linguagem para que haja um entendimento comum da questão socioambiental de modo que resulte na valorização do meio ambiente, da pluralidade cultual, da justiça social e em ações que reduzam ou aniquilem os impactos negativos causados pelos humanos ao ambiente e si próprios.

Ficou evidenciado que Política Municipal de EA no município de Natal, não é de amplo conhecimento da população, pois, provavelmente não haja ampla divulgação da mesma junto à população já que, quando perguntados sobre a existência da mesma, boa parte dos entrevistados desconhece a existência desta política ou afirmam existir mas não está em fase de atuação.

Desconheço (Entrevista 001, feminino, gestora). 
Não existe uma PMEAN e sim ações conjuntas entre Secretarias. (Entrevista 002, feminino, gestora).

Não sei / Não conheço (Entrevista 004, feminino, educadora).

Existe uma política de educação ambiental que no momento está desarticulado devido às mudanças de membros que compõe o grupo. (Entrevista 005, feminino, gestora).

A Constituição Federal traz no Capítulo VI - Do Meio Ambiente, Art. 225, \$ 10, Inciso VI, que todos têm direito ao meio ambiente ecologicamente equilibrado e que, para assegurar esse direito incube ao poder público "promover a educação ambiental em todos os níveis de ensino e a conscientização pública para a preservação do meio ambiente", porém, isso não está acontecendo no município. No entanto, o que foi identificado nesta investigação é que os setores e órgãos responsáveis pelas questões ambientais e educacionais, não tem o apoio necessário para que se tenha a condição necessária e adequada à eficiente aplicação de uma política municipal de educação ambiental, que atenda aos aspectos naturais, sociais, político, culturais e econômicos de Natal.

Os métodos, técnicas e práticas estão elencadas entre palestras, mini-cursos, oficinas, atividades lúdicas e arte-educativas. O atendimento às necessidades da população, de acordo com os temas abordados, descritos anteriormente, é feito de acordo com as demandas e não são planejadas estrategicamente e de forma contínua. Em alguns casos, há uma evidente e fiel reprodução do uso de materiais e métodos recomendados pelo Órgão Gestor da PNEA (Ministério do Meio Ambiente e Ministério da Educação).

As ações do setor são conduzidas diante de duas possibilidades: $1^{\circ}$ através de solicitação dos próprios munícipes (Escolas das redes pública e privada, instituições e entidades organizadas da comunidade civil, conselhos comunitários, associações de bairro, cooperativas, postos de saúde, empresas, igrejas, repartições públicas, universidades) através do envio de ofícios pedindo algum dos serviços de educação ambiental do SEA: Teatro de Mamulengo, Palestras, Oficinas, Material Educativo, desenvolvimento de jogos e brinquedos ecologicamente adequados. $2^{\circ} \mathrm{com}$ a solicitação de atividades realizadas pelas próprias demandas dos gestores dos municípios com a elaboração de projetos e programas de EA, elaboração de cartilhas educativas, participação em eventos do município levando os serviços supracitados para a comunidade em geral, como por exemplo, a semana do meio ambiente.

(Entrevista 003, masculino, gestor).

Palestras, Mini Cursos e Oficinas.

(Entrevista 005, feminino, gestora).

Com relação à EA cabe a Secretaria Municipal de Educação (SME) implementar nas suas unidades de ensino os projetos oriundos do Ministério do Meio Ambiente em parceria com o Ministério da Educação e Cultura, no caso o Programa "Vamos Cuidar do Brasil com as Escolas".

(Entrevista 002, feminino, gestora).

Os recursos necessários ao financiamento das ações e atividades da PMEAN, de acordo com a afirmativa abaixo descrita na entrevista 003, são do Fundo Municipal de Meio Ambiente provenientes de compensação ambiental e multas ambientais aplicadas no âmbito do município 
de Natal. No entanto, não foi possível identificar a efetividade da aplicação destes recursos já que há uma forte evidência da ineficiência da aplicação da PMEAN levando-se em consideração os depoimentos dos próprios entrevistados que apontam contradição quanto à existência, origem e aplicação desses recursos como também a perceptível degradação socioambiental no município de Natal.

O aporte financeiro para a sustentação da política de educação ambiental e meio ambiente do município é proveniente do FUNAM, que é o fundo municipal de meio ambiente onde são depositados um percentual dos valores referentes à compensação ambiental e multas ambientais aplicadas no âmbito do município de Natal.

(Entrevista 003, masculino, gestor).

Recursos financeiros do estado, IDEMA e outros órgãos envolvidos.

(Entrevista 005, feminino, gestora).

Não sei / não conheço

(Entrevista 004, feminino, educadora).

Layrargues (2006) alerta que temos um desafio na Educação Ambiental, que é o de incorporar e construir novos conceitos que atendam a realidade vivida nos diasatuais, de forma que essa educação tenha como um dos focos o exercício da cidadania, "no sentido do desenvolvimento da ação coletiva necessária para o enfrentamento dos conflitos socioambientais" (Ibid, p. 88). Na escola a Educação Ambiental deve ser percebida como estratégia na busca de espaços em que possa haver reflexões e concretizações de atividades, sempre partindo de conhecimentos significativos para o aluno colocando-o em contato com a sua realidade. Dessa forma a Educação Ambiental estará contribuindo para que o indivíduo compreenda as relações de interdependência em seu entorno, a partir de um conhecimento reflexivo, critico de sua realidade biofísica, social, política, econômica e cultural. Então, a partir dessa assimilação da realidade concreta, possam ser geradas atitudes de valorização e respeito por seu ambiente (SANTOS, 2007).

\section{CONCLUSÕES}

A sociedade contemporânea e o ambiente de suas vivências primárias e secundárias vêm se caracterizando por profundas transformações de ordem econômica, política, social, cultural, tecnológica, ambiental e apresentado aos diversos setores sociais o desafio da construção de novos paradigmas e estratégias que resultem nas tão discutidas sociedades de hábitos sustentáveis. A Política Municipal de Educação Ambiental de Natal (PMEAN) em seu Capítulo I, Art. 10- Entende-se por Educação Ambiental os processos por meio dos quais o indivíduo e a coletividade constroem valores sociais, conhecimentos, habilidades, atitudes e competências voltadas para a conservação do meio ambiente, bem de uso comum do povo, essencial à sadia qualidade de vida e sua sustentabilidade. Parece claro afirmar que a educação ambiental entendida como um instrumento de informação, de formação de multiplicadores de atitudes positivas na preservação e conservação ambiental, de valorização e reconhecimento da pluralidade cultural, de fortalecimento da solidariedade e da autonomia dos povos, tem sido 
considerada por muitos estudiosos das questões ambientais como essencial à (re)estruturação da ética planetária e construção de sociedades sustentáveis.

A educação ambiental nasce como um processo educativo que conduz a um saber ambiental materializado nos valores éticos e nas regras políticas de convívio social e de mercado, que implica a questão distributiva entre benefícios e prejuízos da apropriação e do uso da natureza. Ela deve, portanto, ser direcionada para a cidadania ativa considerando seu sentido de pertencimento e co-responsabilidade que, por meio da ação coletiva e organizada, busca a compreensão e a superação das causas estruturais e conjunturais dos problemas ambientais. (SORRENTINO et al., 2005)

$\mathrm{Na}$ busca dessa compreensão a que se refere a citação anterior, muitos estudiosos do conhecimento elaborado e observadores que fazem uma leitura empírica dos fenômenos naturais, das relações ecossistêmicas e das interrelações entre os indivíduos e entre estes o e meio ambiente, têm dado diferentes definições acerca da EA gerando uma conceituação nem sempre consensual conforme afirma Silva (2008, p.47):

Inexiste ainda uma conceituação perfeitamente delimitada e consensual do que seja educação ambiental. O seu conceito ainda se encontra em fase de construção. É por essa razão que encontramos uma pluralidade de definições para o termo educação ambiental e consequentemente uma gama multifacetária de práticas educacionais.

Daí a necessidade de se ter uma Política Municipal de Educação Ambiental e sua inserção na educação escolar e na educação comunitária do cotidiano das pessoas de modo que estas tenham a oportunidade de trocar saberes e experiências que possibilitem o pertencimento socioambiental e proposição soluções para os problemas gerados pela sociedade moderna.

A partir de estudos bibliográficos, das observações e entrevistas foi possível constatar que no momento, apesar de serem desenvolvidas algumas atividades em relação à problemática ambiental, estas são insuficientes e não contribuem para não alcançarmos um ambiente socialmente justo e equilibrado. A falta de comprometimento do poder público municipal, com a sociedade e com o meio ambiente, pode ser um dos fatores principais para os entraves da efetiva implementação da PMEAN. Além disso, precisa-se que os educadores tomem consciência da importância em se ter uma formação continuada, pois, a sociedade está em constante transformação e precisamos está preparados para a prevenção e enfrentamento da problemática ambiental que sempre surgirão, mas que devem ser controladas e minimizadas.

Por meio de todas as entrevistas realizadas, podemos concluir, por hora, que a Educação Ambiental no município de Natal não está tendo a devida atenção. As escolas e os professores estão tendo muita dificuldade em inserir a Educação Ambiental em seu contexto, além destes últimos precisarem de formação continuada e apoio das Secretarias responsáveis pela inserção do tema na educação formal. Segundo os gestores municipais, está havendo um atendimento dessas atividades por meio de demandas apresentadas por essas escolas o que caracteriza uma atuação apenas pontual na educação formal e que pouco contribui com o contexto comunitário local e quiçá com outros locais do planeta.

Embora, se tenha encontrado muitas dificuldades para a aplicação desse trabalho, este serve para se fazer uma análise e reflexão a respeito de nossa formação como educadores e gestores na área da educação. A partir de então, vejo a necessidade de tomarmos uma postura individual voltada para a mudança de comportamento e em relação ao Poder Público para que a 
educação ambiental seja vista como um dos fatores importantes para que se tenha uma sociedade justa e solidária social e ambientalmente.

Por fim, embora estejam sendo tomadas algumas medidas para implementação de uma política de educação ambiental condizente com as necessidades locais, sabe-se que há muito trabalho pela frente, e que não são apenas os governantes os únicos responsáveis. Cabe a cada educador e cidadão conscientizar-se e sensibilizar-se de que é preciso mudar a forma de nos relacionarmos com o mio ambiente colocando em prática ações coletivas que poderão contribuir para uma vida em equidade.

Esse artigo poderá contribuir para que os atuais e futuros gestores ambientais do município possam refletir sobre suas práticas recorrendo a novos conhecimentos teóricos e práticos. Construindo e reconstruindo novos conceitos que permitirão transformações políticas, econômicas, culturais e sociais do município, tendo consciência de que precisam aprender a aprender sobre complexidade socioambiental, que terá como resultado final uma visão holística aos problemas ambientais chegando a soluções práticas e elaboração de novas políticas e estratégias de desenvolvimento.

\section{REFERÊNCIAS}

BRASIL. Constituição. CONSTITUIÇÃO DA REPÚBLICA DO BRASIL: texto constitucional promulgado em 5 de outubro de 1988, com alterações adotadas pelas emendas constitucionais. Brasília: Subsecretaria de Edições Técnicas, 2007.

BRASIL, LEI DE DIRETRIZES E BASES DA EDUCAÇÃO NACIONAL. lei 9394/1996 de 20 de dezembro.

BRASIL. LEI 9795/1999 DE 27 DE ABRIL: Brasília: Diário Oficial, 28/04/1999.

CASTRO, SPAZZIANI, SANTOS. Universidade, meio ambiente e parâmetros curriculares nacionais. In: Sociedade e meio Ambiente: A educação em debate; 4ạ. ed. - São Paulo:Cortez, 2006.

BRASIL. MINISTÉRIO DO MEIO AMBIENTE. Secretaria de Articulação Institucional e Cidadania Ambiental Departamento de Educação Ambiental. Os Diferentes Matizes da Educação Ambiental no Brasil;1997-2007. Brasília, DF:MMA, 2008. (Série Desafios da Educação Ambiental). 290 p.; Texto: Silvia Czapski.

DIAS, Genebaldo Freire. OS QUINZE ANOS DA EDUCAÇÃO AMBIENTAL NO BRASIL: um depoimento; Brasília, v. 10, n. 49, jan./mar. 1991. In: Em Aberto.

FERREIRA, Leila da Costa. A política ambiental no Brasil. In: População, meio ambiente e desenvolvimento: Verdades e contradições; 2a. ed. - Campinas: Unicamp, 1996.

FREIRE, P. Pedagogia do oprimido. 47ä. ed. - Rio de Janeiro: Paz e terra, 2008.

GADOTTI, Moacir. Educar para a sustentabilidade: uma contribuição a década da educação para o desenvolvimento sustentável. São Paulo: editora e livraria Paulo freire, 2009.

GIL, A. C. Métodos e técnicas de Pesquisa Social. 4ạ. ed. São Paulo: Atlas, 1994, p. 207.

JUNIOR, MENDONÇA, SORRENTINO, TRAJBER. Educação ambiental como política pública. São Paulo, v. 31, n. 2, p. 285-299, maio/ago. 2005. In: Educação e Pesquisa.

LAYRARGUES, Philipe Pomier. Educação para a gestão ambiental: a cidadania no enfrentamento político dos conflitos socioambientais. In: Sociedade e meio ambiente: a educação ambiental em debate; 4ạ. Ed. - São Paulo: Cortez, 2006. LEFF, E. Saber ambiental. 4a. ed. Petrópolis: Vozes, 2001.

. Epistemologia ambiental. 3a. ed. - São Paulo: Cortez, 2002.

A complexidade ambiental (coord.). - São Paulo: Cortez, 2003.

LOUREIRO, Carlos Frederico B.. TRAJETÓRIAS E FUNDAMENTOS DA EDUCAÇÃo AMBIENTAL. 3ạ São Paulo: Cortez, 2009.

MEDINA, N. M. e SANTOS, E.C, Educação Ambiental: Uma metodologia participativa de formação. Petrópolis, Vozes, 2001.

MINAYO, M.C. e DESLANDES, S.F. Caminhos do pensamento: epistemologia e método. Rio de Janeiro: Fiocruz, 2002. 
REIS, Marília Freitas De Campos Tozoni -. EDUCAÇÃo AMBIENTAL: natureza razão e história. 2a Ed. Campinas, São Paulo: Autores Associados, 2008.

RIO BRANDE DO NORTE. LEI 0280/2009 DE 14 DE JULHO DE 2009: Natal: Diário Oficial, 16/04/2009.

SAITO, C. H. Política nacional de educação ambiental e construção da cidadania:Desafios contemporâneos. In: Educação Ambiental: Abordagens Múltiplas. Porto alegre: Artmed, 2002.

SANTOS, Elizabeth da Conceição et al. (Ed.). Educação Ambiental: Universidade do Estado do Amazonas. Manaus: Uea Edições, 2007.

SILVA, Aguinaldo Salomão. EDUCAÇÃO AMBIENTAL: ASPECTOS TEÓRICOS-CONCEITUAIS, LEGAIS E METODOLÓGICOS. Juiz de Fora, v. 1, n. 2, p. 45-61, 2. sem. 2008. In: Educação em Destaque. 